\title{
Configuration and Control of Cycloconverter for Low Frequency AC Transmission System in 500kv Transmission Line
}

\author{
War War Naing ${ }^{1}$ and Myint Thuzar $^{2}$ \\ Research Scholar ${ }^{1}$ and Professor ${ }^{2}$ \\ ${ }^{1}$ Department of Electrical Power Engineering \\ Mandalay Technological University, \\ The Republic of the Union of Myanmar \\ Mandalay
}

\begin{abstract}
Today, the highest voltage level of the AC power transmission line is 500kV in Myanmar. The highest voltage level encounters the difficulties of the material and environment issues. If it is a long-distance transmission, its power losses and voltage regulation are increasing. High voltage $50 \mathrm{~Hz}$ AC transmission system has many limitations, so a high voltage Low-Frequency AC (LFAC) transmission system has been proposed as a new alternative technology for transmission of power between Meikhtila and Taungoo transmission system. The low-frequency AC transmission system is the $500 \mathrm{kV}$ transmission system. The low-frequency AC transmission system utilizes the low frequency for transmission of power in this transmission line. This system would like to be built a low-frequency AC transmission system that used two cycloconverter at the sending end and the receiving end. This paper focuses on the simulation for three-phase six pulse bridge cycloconverter for low-frequency AC (LFAC) transmission system. This system uses cycloconverter model and cycloconverter control that included voltage control, current limiter, extinction angle control and Virtual Synchronous Generator (VSG) which used the Runge-Kutta Method between Meikhtila and Taungoo transmission system. This converter control model used in LFAC system satisfies in long-distance transmission and increases voltage level in the transmission line because our country increases in load demands. The MATLAB-SIMULINK model for threephase six pulse bridge cycloconverter has been constructed for a $500 \mathrm{kV}$ LFAC transmission system. LFAC system described that it is nearly 800MW the maximum active power transfer capacity by using the cycloconverter control.
\end{abstract}

Key Words: Low frequency AC transmission, Cycloconverter design, Virtual Synchronous Generator control, Firing angle.

\section{INTRODUCTION}

Nowadays, the capacitance of HVAC power conductors lead to significant charging current, which reduces the active power transmission capacity and limits the transmission distance. It is convenient for short distance transmission system. Increasing distance and capacity mainly depends on raising voltage level of transmission lines in AC transmission system [1]. So, low frequency $\mathrm{AC}$ transmission system used two cycloconverter that is shown in Figure 1. It is a static frequency changer, which can convert AC power at one frequency to power at another frequency. It can also provide bidirectional power flow. Normally, it is used to step down the frequency of power at the sending end. At receiving end, another cycloconverter will step up the frequency of power from the low frequency side to the nominal frequency of the grid. The new transmission system uses fractional frequency (i.e. $50 / 3 \mathrm{~Hz}$ in our study) to reduce the reactance of the AC transmission system, hence can increase transmission capacity and remarkably improve its operating performances [2].



Figure.1: Block diagram of low frequency ac transmission using Cycloconverters 


\section{PRINCIPLE AND CONTROL FOR LFAC TRANSMISSION}

In this section, principle of LFAC transmission system, control strategies and construction of cycloconverter are briefly classified. And then the control method and VSG control scheme are also described.

\subsection{Principle of LFAC Transmission System}

For AC transmission system, the active power(p) transmitting over the transmission lines[3], which should be able for connecting substations across the transmission line, which can be expressed by ;

$$
\mathrm{P}=\frac{\mathrm{V}_{\mathrm{S}} \mathrm{V}_{\mathrm{R}}}{\mathrm{X}_{\mathrm{L}}} \sin \delta
$$

Where $V_{S}$ and $V_{R}$ are the sending end voltage and receiving end voltages, respectively. $\mathrm{X}_{\mathrm{L}}$ is the line reactance. $\delta$ is the transmitting angle. Eq. (1) is valid when the conductor is short that neglects the effect of the line angle, increasing transmitting power is either by increasing the voltage level or lowering the impedance of the cable[3]. Furthermore, with the fixed sending end voltages, the only way is to improve the transmission capability by reducing the inductive reactance of the conductor. The reactance is proportional to power frequency f;

$$
X_{L}=2 \pi f L
$$

Where $\mathrm{L}$ is the total inductance over the line, decreasing the electricity frequency can proportionally increase the transmission capability. The LFAC system uses low-frequency to reduce the reactance of the transmission system thus, its transmission capacity can be increased several fold. For instance, when frequency is $50 / 3 \mathrm{~Hz}$, the theoretically transmission capability can be raised three times[4]. The LFAC system can also improve the voltage stability given the same amount of reactive power transmission as given in Eq. (3);

$$
\Delta \mathrm{V}=\frac{\mathrm{QX}_{\mathrm{L}}}{\mathrm{V}^{2}}
$$

Where $\Delta \mathrm{V}$ is the voltage drop over the cable, $\mathrm{V}$ is the nominal voltage, $\mathrm{Q}$ is the reactive power flow of the cable. Because the impedance is reduced in the LFAC system due to the power lower grid frequency, the voltage drop over the cable is proportionally reduced accordingly.

\subsection{Three Phase Six Pulse Cycloconverter For LFAC System}

Figure 2 shows the three phase six pulse cycloconverter. It is a static frequency changer, which can convert AC power at one frequency to power at another frequency. It can also provide bidirectional power flow and two cycloconverter are used at the sending end and at the receiving end. This system requires the cycloconverter to operate in its inversion mode. The cycloconverter controls the voltage by adjusting the firing angle that is compared reference angle side in the control blocks. For low frequency AC transmission system, three phase to three phase bridge cycloconverter is utilized. It is also known as six pulse cycloconverter or 36 thyristor cycloconverter.



Figiure 2. Three Phase Six Pulse Bridge Cycloconverter

\subsection{Control Strategies for LFAC Transmission System}

Considering the mode control of the cycloconverter, this converters works as a two-set of HVDC anti-parallel connections and their inputs are a sinusoidal waveform instead of a constant value. The voltage control scheme of cycloconverter can be designed by using HVDC concepts and then the control block diagram is shown in Figure 3. The reference voltage is the reference angle side of the low frequency, whereas the other low frequency side is measured instantaneous voltage. 


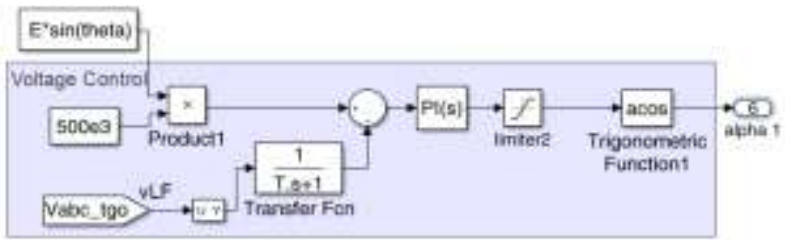

Fig 3.Voltage control of LFAC[5]

For the protection of over current and commutation failure, a current limiter and extinction angle control are applied in this system. The current limiter is used to limit over current during transmission of power where the current of low frequency is measured that is instantaneous current on low frequency side. The current control scheme of cycloconverter is shown in Figure 4.

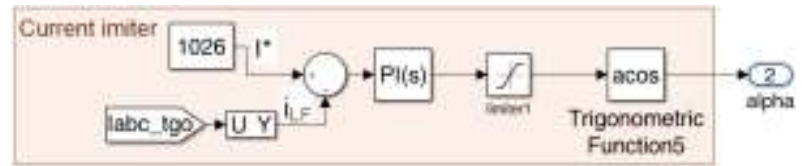

Fig 4.Current limiter of LFAC[5]

In the extinction angle protection, obtained $\alpha_{i}$ is compared with the firing angle from the extinction angle controller. If the obtained $\alpha_{i}$ is greater than the $\alpha_{i}$ from the extinction angle controller, obtained $\alpha_{i}$ is changed to the value from extinction angle controller.

For line commutated converters, it has some overlapping angle due to the commutation reactance. The constant extinction angle control $(\gamma)$ is used to avoid commutation failure. As shown in Figure 5, this extinction angle control works by comparing gamma reference with gamma measured, then the minimum firing angle is chosen to be gating pulse for cycloconverters. The typical value of extinction angle $(\gamma)$ is set at $15^{\circ}$ for $50 \mathrm{~Hz}$ of the AC system.

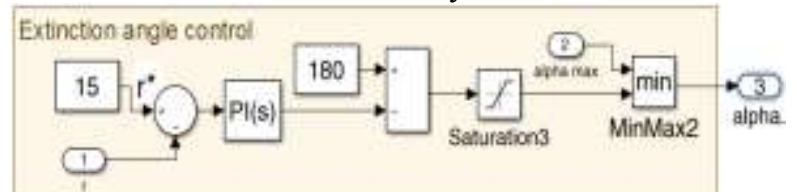

Fig 5.Extinction angle control of LFAC[5]

\subsection{Runge-Kutta Method}

For simplification, the damping factor D is considered as a small constant parameter. An algorithm based on the Runge-Kutta method is used to solve the angular frequency $\omega_{\mathrm{m}}$ following the block diagram as shown in Figure 6 .The calculated $\omega_{\mathrm{m}}$ provides the ferequency reference for the governor model and phase reference $\theta_{\mathrm{m}}$ through an integrator. $\mathrm{P}_{\text {base }}$ is the rated capacity of transmission power.

\subsection{VSG Based Controller}

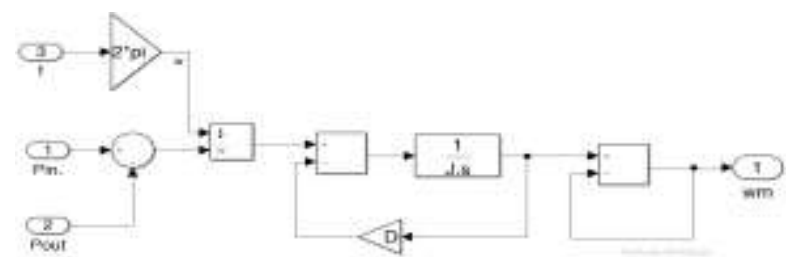

Fig 6. Runge-Kutta Method used in VSG control scheme

The governor model is shown in Figure 7. It is implemented to tune the input power command based on the frequency deviation. The transfer function of the governor control can be expressed as Eq. (4), where $K_{p}=5, T_{d}=0.1$ were chosen from trialand-error tuning method[6].

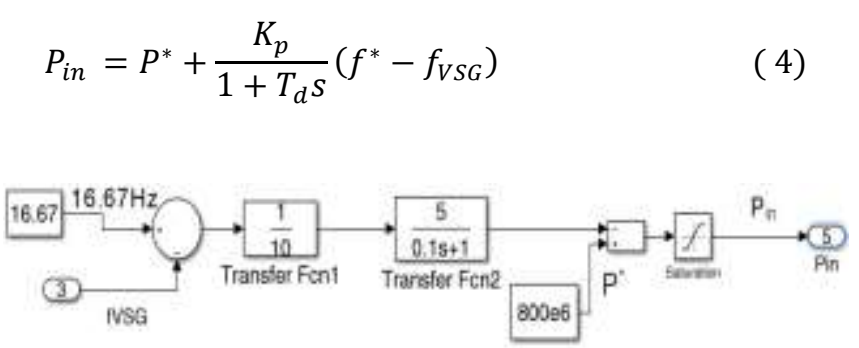

Fig 7.Governor control scheme

In the VSG control part as shown in Figure 8, $\mathrm{P}_{\mathrm{in}}, \mathrm{P}_{\text {out }}$ and low frequency side frequency $\left(\mathrm{f}_{\mathrm{g}}\right)$ are inputs of the VSG control unit. In each control cycle, the momentary $\omega_{\mathrm{m}}$ is calculated via the application of the forth-order Runge-kutta iterative method inside the VSG block to generate the virtual phase angle $\theta_{\mathrm{i}}(\mathrm{i}=1,2,3)$ sent through the voltage control unit. 


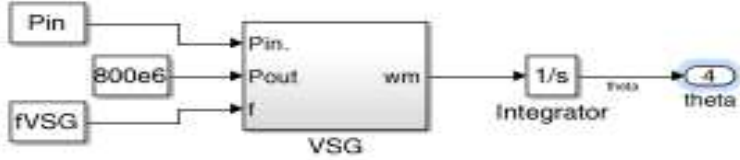

Fig 8.VSG control scheme[6]

As for the voltage control scheme, the concept of the control operation is the same as the voltage control scheme as described in the above section. When a disturbance occurs, or more load shares are added to the system, the system can stabilize itself by regulating voltage using this control. The current limiter works by comparing the rating current with measured current from the low frequency side to generate the firing angle to the cycloconverter, which can limit over current by limiting firing angle to the cycloconverter. Also, extinction angle control $(\gamma)$ is included to avoid commutation failure in a converter.

\subsection{Output Voltages for Various Firing Angle}

According to the following equation and table, the firing angle is between $40^{\circ}$ and $50^{\circ}$ to get the output voltage at the low frequency side is nearly $500 \mathrm{kV}[7]$. For three phase bridge cycloconverter, the fundamental output voltage at low frequency side is;

$$
\begin{aligned}
\mathrm{V}_{\mathrm{LF}} & =\frac{3 \times \sqrt{2}}{\pi} \mathrm{V}_{\mathrm{LL}} \cos \alpha \\
& =\frac{3 \times \sqrt{2}}{\pi} \times 500 \times 10^{3} \cos \alpha(\alpha=0) \\
& =675.24 \mathrm{kV}
\end{aligned}
$$

Where $\alpha=$ the firing angle

$\mathrm{V}_{\mathrm{LF}}=$ the rms value of line to neutral voltage at the low frequency side

$\mathrm{V}_{\mathrm{LL}}=$ the rms value of line to line voltage at the standard frequency side

Table I LOW FREQUENCY SiDE VOLTAGES For VARIOUS FIRING ANGLES

\begin{tabular}{|c|c|c|}
\hline SL. No & $\begin{array}{c}\text { Firing Angle } \\
\text { (Deg) }\end{array}$ & $\begin{array}{c}\text { Low Frequency Side } \\
\text { Voltage (kV) }\end{array}$ \\
\hline 1 & 0 & 675.24 \\
\hline 2 & 10 & 664.98 \\
\hline 3 & 20 & 634.52 \\
\hline 4 & 30 & 584.77 \\
\hline 5 & 40 & 517.26 \\
\hline 6 & 50 & 434.04 \\
\hline 7 & 60 & 337.62 \\
\hline
\end{tabular}

\section{SIMULINK MODEL FOR LFAC TRANSMISSION SYSTEM}

Figure 9 shows that the three phase six pulse cycloconverter is modelled in MATLAB-SIMULINK using power system block set. The reference frequency used is $16.67 \mathrm{~Hz}$, the transmitted reference power is 800MW for the LFAC transmission system. Voltage and current simulation results are formed from this model. With these simulation results, it can be confirmed that the proposed control scheme properly works for the LFAC transmission system. Table II describes the system parameters in the SIMULINK model of LFAC transmission system.

\section{Table II SYSTEM PARAMETERS}

\begin{tabular}{|l|c|}
\hline Phase-to-phase voltage (Vrms) at source side & $16 \mathrm{kV}$ \\
\hline Frequency (Hz) at source side & $50 \mathrm{~Hz}$ \\
\hline 3-phase short-circuit level at base voltage(VA) & $15000 \mathrm{MVA}$ \\
\hline Rated voltage (Vrmsph-ph) & $500 \mathrm{kV}$ \\
\hline Number of phases [ N ] & 3 \\
\hline Frequency used for rlc specification(Hz) & $2.69 \mathrm{E}-05$ \\
\hline Resistance per unit length $(\mathrm{Ohms} / \mathrm{km})$ & $9.62 \mathrm{E}-07$ \\
\hline Inductance per unit length $(\mathrm{H} / \mathrm{km})$ & $7.971607 \mathrm{e}-12$ \\
\hline Capacitance per unit length (F/km) & 420 \\
\hline Line length (km) & $33 \mathrm{kV}$ \\
\hline Nominal phase-to-phase voltage Vn (Vrms) at load side & \\
\hline
\end{tabular}


International Journal of Advances in Scientific Research and Engineering (ijasre), Vol 5 (11), November-2019

\begin{tabular}{|l|c|}
\hline Nominal frequency fn $(\mathrm{Hz})$ at load side & $50 \mathrm{~Hz}$ \\
\hline Active power $\mathrm{P}(\mathrm{W})$ & $800 \mathrm{MW}$ \\
\hline
\end{tabular}

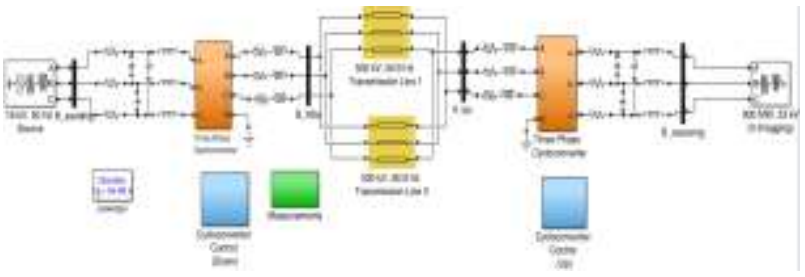

(a)

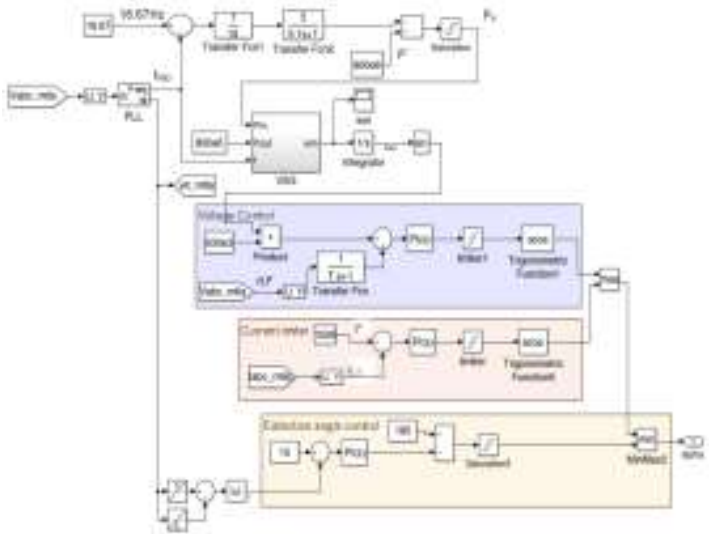

(b)

Fig 9.Simulink model of: (a) low frequency AC transmission system and (b) Complete control scheme with VSG

\section{SIMULATION RESULTS AND ANALYSIS}

The simulation results are obtained from the above Simulink model. Figure 10 shows the line to line voltage waveforms at the sending end nearly $16 \mathrm{kV}$ at $50 \mathrm{~Hz}$ and figure 11 shows the voltage waveforms of Meikhtila bus nearly $500 \mathrm{kV}$ at $16.67 \mathrm{~Hz}$ for full load condition. Figure 12 shows the line to line voltage waveforms of receiving end bus nearly by $33 \mathrm{kV}$ at $50 \mathrm{~Hz}$ under full load condition.

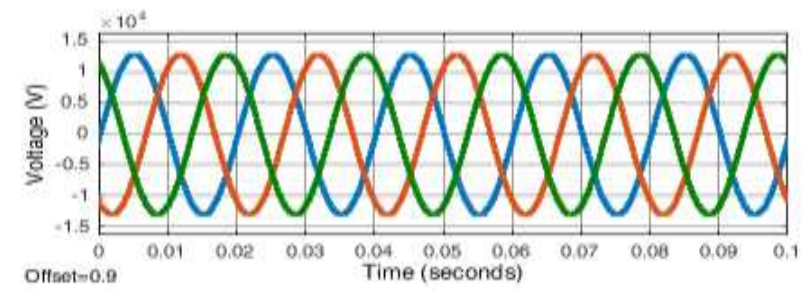

Fig 10. Voltage Waveform at Sending Bus for Full Load with Rated Frequency $50 \mathrm{~Hz}$

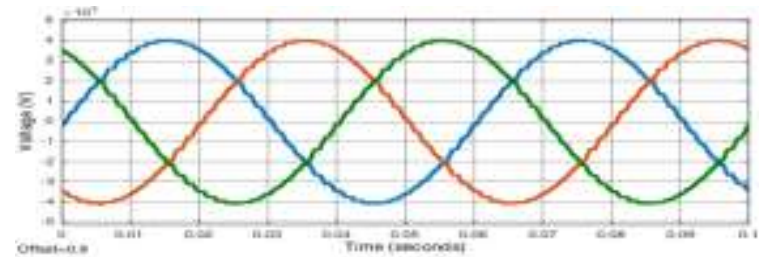

Fig 11. Voltage Waveform at Meikhtila Bus for Full Load with Low Frequency $16.67 \mathrm{~Hz}$



Fig 12. Voltage Waveform at Receiving Bus for Full Load with Rated Frequency 50 Hz

Figure 13,14 and 15 illustrate the RMS line voltages at sending bus, LFAC system and receiving bus respectively. The voltages are within regulation limits. 


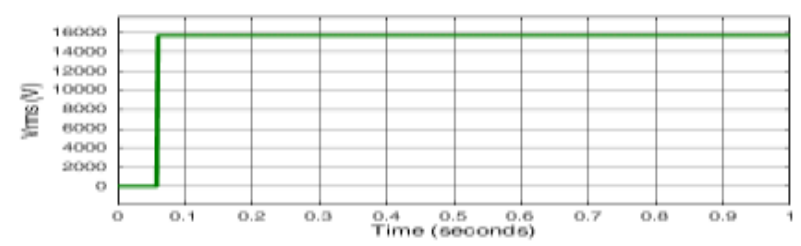

Fig 13. Voltage RMS Value at Sending Bus for Full Load with Rated Voltage 16 kV

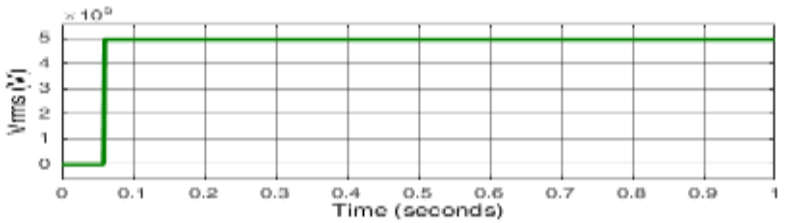

Fig 14. Voltage RMS Value at Meikhtila Bus for Full Load with Rated Voltage 500 kV

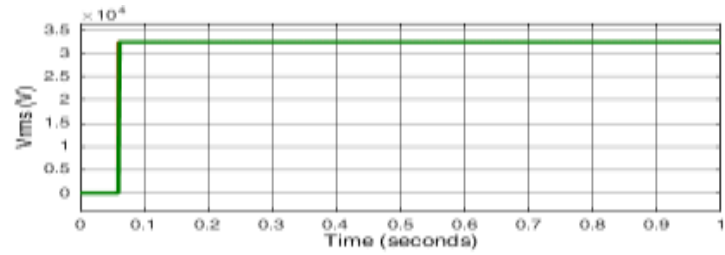

Fig 15. Voltage RMS Value at Receiving Bus for Full Load with Rated Voltage 33 kV

Figure 16 and 17 shows the active power transfer conditions. This system would like to get receiving end power nearly 800MW, so the sending end active power supplied 815MW. The modelling system is not described for Figure 16 and 17[7]. This system is constructed without cycloconverter. Thus, this system is lossed 15MW. So, the transmission system would like to describe with cycloconverter by controlling the firing angle within the regulation voltage limit to get nearly $800 \mathrm{MW}$.

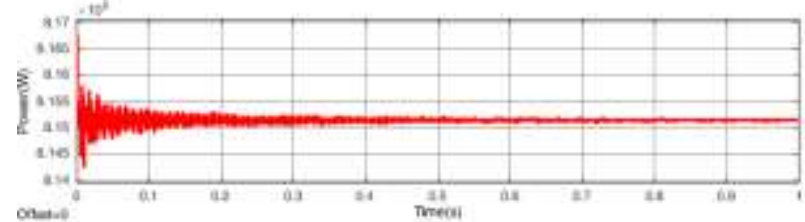

Fig 16.Sending End Active Power at 50Hz Transmission System[7]



Fig 17.Receiving End Active Power at 50Hz Transmission System[7]

Figure 18, 19, and 20 illustrate the active power at sending bus, LFAC system and receiving bus respectively by using cycloconverters. In this system the sending active power is $800 \mathrm{MW}$ and then the receiving end active power is nearly $800 \mathrm{MW}$ with fewerly losses. The following diagram shows the maximum active power transfer capacity(nearly $800 \mathrm{MW}$ ). Thus the transmission system with cycloconverters is more suitable than the system without cycloconverters by seeing the results.

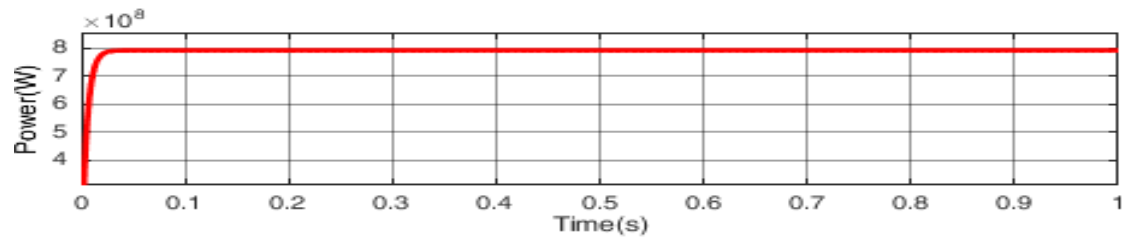

Fig 18. Sending end Active Power at the source side $(50 \mathrm{~Hz})$



Fig 19. Sending end Active Power at LFAC transmission system of Meikhtila bus (50/3Hz) 




Fig 20. Receiving end Active Power at the load side (50Hz)

\section{CONCLUSION}

With the advancement in power electronic technology, the low frequency AC transmission system become popular due to its benefits. In LFAC application, design of cycloconverter is critical important. In this paper, the design and simulation of three phase cycloconverter is presented for $500 \mathrm{kV}$ transmission system. Modeling and simulations are executed by using Matlab/Simulink. According to the simulation results, the cycloconverter can provide $500 \mathrm{kV}$ line voltage at $16.67 \mathrm{~Hz}$. The firing angle is applied between $40^{\circ}$ and $50^{\circ}$ (to get nearly $500 \mathrm{kV}$ and $800 \mathrm{MW}$ ). The voltage drop and harmonic distortion are negligible. Therefore, the design calculations for output voltage of cycloconverter are applicable for LFAC transmission systems. In this paper, maximum active power transfer capacity are described in LFAC transmission system.

\section{ACKNOWLEDGMENT}

The author is deeply gratitude to Dr.Wunna Swe, Professor and Head, Department of Electrical Power Engineering, Mandalay Technological University for his kindly permission and suggestion throughout the preparation of paper. I would like to thank to all of my teachers, Department of Electrical Power Engineering, Mandalay Technological University, for their kind permission, providing encouragement and giving helpful advices, thoroughly proof-reading this paper and giving useful remarks on it. Finally, the author wishes to express her deepest gratitude to her parents for providing the funding for the large majority of her education.

\section{REFERENCES}

1. T. Funaki and K.Matsuura, "Feasibility of the lower frequency AC transmission", in proc. IEEE Trans. Power Eng. Soc. Winter Meeting, vol. 4, (2000), pp. 2693-2698.

2. Pichetjamroen, Achara, "Studies on Configuration and control of Low-Frequency AC Transmission System Using Cycloconverters", Osaka University, Sep. 2016.

3. Yongnam Cho,"Modeling methodology of converters for HVDC systems and LFAC systems integration and transmission of Renewable energy", Aug. 2013.

4. X. Wang, C. Cao, and Z. Zhou, "Experiment with fractional frequency transmission system, IEEE Trans. Power Syst., vol. 21, no. 1, (2006) February, pp. 372-377.

5. Xifan Wang, and Xiuli Wang, "Feasibility Study of Fractional Frequency Transmission System," IEEE Trans. Power Syst., vol.11, no.2, pp. 962-96, 7, May. 1996.

6. Wang XF, Cao CJ, and Zhou ZC, "Experiment on the fractional frequency transmission system," IEEE Trans. Power Syst., vol.21, no.1, pp. 372-377, Feb. 2006.

7. War Naing, "Comparative Analysis of Low-Frequency AC Transmission System and HVAC Transmission System in 500kV Transmission Line", ICSE Trans, Dec 2018. 